\title{
Üzüm Suyunun Isıtılmasında Güncel Elektriksel Isıtma Uygulaması; Ohmik Isıtma
}

\author{
Serdal Sabanc1 ${ }^{*}$ \\ 1* Munzur Üniversitesi, Sağlık Bilimler Fakültesi, Beslenme ve Diyetetik Bölümü, Tunceli, Türkiye, (ORCID: 0000-0003-1630-0799), serdalsabanci@hotmail.com
}

(İlk Geliş Tarihi 24 Nisan 2020 ve Kabul Tarihi 25 Ekim 2020)

(DOI: $10.31590 /$ ejosat.726556)

ATIF/REFERENCE: Sabanc1, S. (2020). Üzüm Suyunun Isıtılmasında Güncel Elektriksel Isıtma Uygulaması; Ohmik Isıtma. Avrupa Bilim ve Teknoloji Dergisi, (20), 466-471.

Öz

Gelişen teknoloji ile beraber güncel elektsiksel ısıtma işlemlerinin uygulaması giderek artmaktadır. Geleneksel ısıtma işlemine alternatif güncel elektriksel ısıtma yöntemlerinden birisi de Ohmik 1sıtma işlemidir. Ohmik 1sıtma işlemi katı/sıvı maddeden alternatif akım geçilmesiyle ürün içerisinde 1 sı jenerasyonuna bağlı olarak ürünün 1sınma prensibine dayanmaktadır. Ohmik 1sıtma işlemi özellikle hızlı, homojen ve verimli bir 1sıtma olarak kabul edilmektedir. Mevcut çalışmada, ohmik ısıtma işlemi yardımıyla (sabit voltaj gradyanında $13 \mathrm{~V} / \mathrm{cm})$ üzüm suyunun $20^{\circ} \mathrm{C}$ 'den $90^{\circ} \mathrm{C}$ 'e kadar 1 sıtılması ve bu sicaklıkta $\left(90{ }^{\circ} \mathrm{C}\right)$ farklı işlem süresinde $(0,20,40 . v e$ $60 \mathrm{dk}$.) tutularak, üzüm suyunun bazı kalite özelliklerinin incelenmesi amaçlanmaktadır. Ayrıca işlem sırasında ohmik ssıtma için önemli özelliklerinden olan elektriksel iletkenlik değerinin incelenmesi ve sabit sicaklıkta $\left(90^{\circ} \mathrm{C}\right)$ farklı tutma sürelerinde toplam harcanan enerji değerinin belirlenmesi amaçlanmıştır. Üzüm suyunun $20^{\circ} \mathrm{C}$ 'den $90{ }^{\circ} \mathrm{C}$ 'ye 1 sınma süresi $311 \pm 5.01 \mathrm{~s}$ olarak belirlenirken, zamana bağlı sıcaklık değişiminin lineer eğilimde olduğu tespit edilmiştir. Ayrıca sıcaklık arttıkça elektriksel iletkenlik değerinin arttığ 1 belirlenmiştir. Üzüm suyunun 1sıtma işlemi sırasındaki elektriksel iletkenlik değerinin $0.144-0.582 \mathrm{~S} / \mathrm{m}$ arasında değiştiği bulunmuştur. Ayrıca ohmic 1sıtma uygulaması sırasında sabit sıcaklıkta tutma süresi arttıkça toplam harcanan enerji değerinin arttığı ancak ortalama güç değerinin ise azaldığı bulunmuştur. Üzüm suyunun ısıtılması ve sabit sıcaklıkta tutma sırasında bazı kalite özelliklerinde değişim incelenmiştir. Özellikle 1sıl işleme duyarlı olan Toplam Fenolik Madde (TFM) miktarının 1sıtma ve sabit sıcaklıkta tutma sürelerindeki üzüm suyundaki miktarının Galik asit eşdeğeri cinsinden 466-367 mg/L arasında olduğu belirlenmiştir. Bunun yanısıra üzüm suyunun farklı sabit sıcaklıkta tutma işlemine bağlı olarak hidroksimetilfurfural (HMF) içeriğinin 0.60-4.71 ppm arasında olduğu tespit edilmiştir. Sonuç olarak kalite kriterlerinden olan TFM miktarı ve HMF içeriği üzerine $90^{\circ} \mathrm{C}$ 'de tutma süresi üzerine etkisi olduğu belirlenmiştir $(\mathrm{p}<0.05)$.

Anahtar Kelimeler: Ohmik 1sitma, Elektriksel iletkenlik, TFM, HMF.

\section{Application of Electrical Heating Method for Grape Juice; Ohmic Heating}

\begin{abstract}
The application of current electrical heating processes is increasing with the developing technology. One of the current electrical heating methods as an alternative to the traditional heating process is Ohmic heating. Ohmic heating process is based on the heating principle that depends on the heat generation in the product by passing alternating current from the solid / liquid substance. Ohmic heating is regarded as a particularly fast, homogeneous and efficient heating. In the present study, with the help of ohmic heating process (13 $\mathrm{V} /$ $\mathrm{cm}$ at constant voltage gradient), the grape juice is heated from $20{ }^{\circ} \mathrm{C}$ to $90{ }^{\circ} \mathrm{C}$ and kept at a constant temperature for 4 different processing times $(0,20,40$ and $60 \mathrm{~min}$.) It was aimed to examine some quality characteristics of grape juice. In addition, it was purposed to examine the electrical conductivity value, which is one of the important properties for ohmic heating during the process, and to determine the total spent energy value for the waiting time at different constant temperature $\left(90{ }^{\circ} \mathrm{C}\right)$. While the heating time of grape juice from $20^{\circ} \mathrm{C}$ to $90^{\circ} \mathrm{C}$ was determined as $311 \pm 5.01 \mathrm{~s}$, it was stated that the temperature change due to time has a linear trend. In addition, it has been determined that as the temperature increases, the electrical conductivity value increases. It has been found that the electrical conductivity value of grape juice during the heating process varies between $0.144-0.582 \mathrm{~S} / \mathrm{m}$. In addition, during the ohmic heating application, as the holding time increases, the total consumed energy value increases but the average power value decreases. The changes in some quality characteristics during the heating of grape juice and holding at constant temperature were investigated. It was determined that the amount of Total Phenolic Content (TFC), which is particularly sensitive to heat treatment, in grape juice during the heating and waiting periods was between $466-367 \mathrm{mg} / \mathrm{L}$ in terms of Galic acid equivalent. In addition, it was found that the hydroxymethylfurfural (HMF) content of grape juice was between 0.60-4.71 ppm depending on the process of holding at different constant temperature. As a result, it was concluted that it influences the TFC amount and HMF content, which are among the quality criteria, on the waiting time at $90{ }^{\circ} \mathrm{C}(\mathrm{p}<0.05)$.
\end{abstract}

Keywords: Ohmic heating, Electrical conductivity, TPC, HMF.

*Sorumlu Yazar: serdalsabanci@hotmail.com 


\section{Giriş}

2017 yılı FAO verilerine göre, üzüm üretimi dünyada 74.276.583 milyon ton olurken, Avrupa'da 25.958.501 ton olarak gerçekleşmiştir. Türkiye ise yaklaşı olarak 4.200.000 milyon ton ile önemli bir üzüm üreticisidir. Bu değer, dünyadaki üzüm üretiminin yaklaşık \%6'sına karşıllık gelirken, Avrupa'daki üzüm üretiminin ise yaklaşık \%20'sini oluşturmaktadır (FAO, 2019). Bu nedenle de üzüm, Türkiye'de önemli bir tarım ürünüdür. Üzüm özellikle sofralık olarak taze ve kurum üzüm olarak tüketilmesinin yanında Türkiye'de sanayide üzüm suyu, pekmez, pestil, şarap, sirke gibi endüstriyel ürünler için hammadde olarak da kullanılmaktadır (Kiraca et al., 2017).

Gıda maddelerinin (sıvı veya katı) 1sıtılması amaciyla genellikle sanayide indirek ssitma olarak bilinen buhar kaynaklı veya fosil yakıt kaynaklı ısıtma teknikleri kullanılmaktadır. Ancak gıda ürünlerinin 1sitılması sırasında 1sıtma yüzeyi ile gıda ürünlerinin temaslı kısımlarında ani isınmalar meydana gelerek istenmeyen bileşenler (HMF, furfural, karemelizasyon vb.) ve kalite kayıları (TFM, antioksidant, besin, aroma vb.) meydana gelmektedir. Bu olumsuzlukları gidermek amacıyla araştırmacılar alternatif güncel ısıtma teknikleri ve/veya isıl olmayan teknikleri incelemektedir. Bu bağlamda kullanılan başlıca alternatif, güncel elektriksel isitma teknikleri mikrodalga 1sitma, ohmik isitma, infraret isitma ve radyo frekans isitma olarak bilinmektedir (Baysal et al., 2011).

Ohmik ısıtma işlemi gıda maddesinin içerisinden alternatif akım geçilerek, ürünün göstermiş olduğu dirence bağlı olarak ürün içerisinde meydana gelen 1s1 jenerasyonu sonucu ürünün ısınma prensibine dayanmaktadır. Literatürde ohmik ısıtma, joule 1sıtma, elektriksel direnç ssıtma gibi isimler ile ifade edilmektedir. Ohmik 1sıtma hızlı, homojen ısıtma ve verimliliği yüksek bir 1sıtma tekniği olarak pek çok çalışmada ifade edilmiştir. Ohmik ısıtma işleminin gıda uygulamaları, pastörizasyon, sterilizasyon, haşlama, çözündürme, pişirme, destilasyon, ekstraksiyon, evaporasyon $\mathrm{vb}$ proseslerde uygulama alanları bulunmakta ve incelenmektedir. Ayrıca ohmik 1sıtmanın ekstraksiyon, osmotik kurutma ve kurutma işleminde ön işlem olarak uygulamaları bulunmaktadır (Baysal et al., 2011; İçier, 2012; İncedayi et al., 2019).

Açık literatür incelendiğinde, meyve ve meyve türevleri için önemli kalite kriteri olarak kabul edilen TFM miktarı ve TFM miktarının değişiminin incelendiği çalışmalar tespit edilmiştir. TFM miktarının incelendiği üvez meyvesi (Bayram et al., 2019), tıbbi ve aromatik bitkiler (Karadağ, 2019), siyah ve yeşil çay (Akarca et al., 2018), soğuk sıkım kiraz çekirdeği (Atik et al., 2019) vb. pek çok geniş gıda ürünleri üzerinde çalışmalara rastlanmaktadır. Ohmik 1sitma uygulamasında (1sitma, evasporasyon vb.) önemli kalite kriterlerinden birisi olan TFM miktarı tespitnin sınırlı sayıda olduğu belirlenmiştir (Guida et al., 2013; İcier, 2010; Yildiz et al., 2009). Diğer önemli bir değerlendirme kriteri ise isıl işlem sırasında oluşan hidroksimetilfurfural (HMF) miktarının tespit edilmesidir. Ancak yazarın bilgisi dahilinde ohmik ısıtma işlemi sırasında meydana gelen HMF ile sınırlı sayıda çalışma olduğu tespit edilmiştir (Louarme et al., 2012; Sabanci et al., 2018; Sabanc1, 2017).

$\mathrm{Bu}$ çalışmanın temel amacı, üzüm suyunun ohmik ısıtma kullanılarak $90^{\circ} \mathrm{C}$ ye kadar isitilmasi ve ssitma sirasinda meydana gelen elektriksel iletkenlik değişiminin incelenmesidir. Ayrıca sabit sicaklıkta $\left(90^{\circ} \mathrm{C}\right)$ farklı tutma sürelerinde $(0-60$ dakika $)$ tutarak bazı kalite değişimlerinin incelenmesi ve toplam harcanan enerji değişimi belirlenerek ohmik 1sıtma işleminin ortalama güç değerinin belirlenmesi amaçlanmaktadır.

\section{Materyal ve Metot}

\subsection{Materyal}

Erzincan’a özgü olan üzümler (Cimin Üzümü (Vitis vinifera)) yerel bir marketten temin edilmiş ve üzüm örnekleri katı meyve sıkacağı kullanılarak üzüm suyu elde edilmiştir. Elde edilen üzüm suyu $6000 \mathrm{rpm}$ değerinde 10 dakika santrifüj işlemine tabi tutulmuştur. Ohmik ssıtma uygulamasına kadar $-18^{\circ} \mathrm{C}$ 'de $500 \mathrm{ml}$ şişelerde depolanmıştır. Ohmik ısıtma uygulamasından bir gün önce $+4{ }^{\circ} \mathrm{C}$ 'ye çıkarılmış ve çözündürme işlemine tabi tutulmuştur.

\subsection{Yöntem}

\subsubsection{Ohmik Isttma Uygulamast}

Üzüm suyunun 1sıtılmasında kullanılan ohmik 1sıtma işleminin şematik gösterimi Şekil 1'de verilmiştir. Ohmik 1sıtma sistemi güç kaynağı, izoletrafo, özel tasarım mikroişlemci ve bilgisayardan oluşmaktadır. Ohmik test hücresinin boyutu $7 \mathrm{~cm}$ uzunluğunda, $10 \mathrm{~cm}$ yüksekliğinde ve $6 \mathrm{~cm}$ genişliğinde dörtgen kesitli olarak ayarlanmış ve elektriğe iletkenliğine karşı izole olan polioksimetilenden yapılmıştır. Ohmik 1sıtma işleminde kullanılan elektrot $1 \mathrm{~mm}$ kalınlığına sahip paslanmaz çelikten oluşmaktadır. İşlem sırasında akım, voltaj ve sıcaklık değerleri özel yapım mikroişlemci ile $1 \mathrm{~s}$ aralıklarla kayıt altına alınmış ve sıcaklık ölçümleri için T-tipi izole isıleş kullanılmıştır. Ohmik 1sıtma işlemi sabit voltaj gradyanında $(13 \mathrm{~V} / \mathrm{cm})$, sabit sıcaklık altında 4 farklı sürede (0-60 dakika) 1 sıl işleme tabi tutulmuştur. Ohmik ısıtma için üzüm suyu örnekleri $20^{\circ} \mathrm{C}$ 'den $90^{\circ} \mathrm{C}$ 'ye kadar 1sıtılmış, sabit sıcaklıkta tutma açma/kapama yapılarak sağlanmıştır. Üzüm suyunun Suda Çözünür Kuru Madde (SÇKM) miktarı dijital refrakto metre yardımıyla belirlenmiştir. 


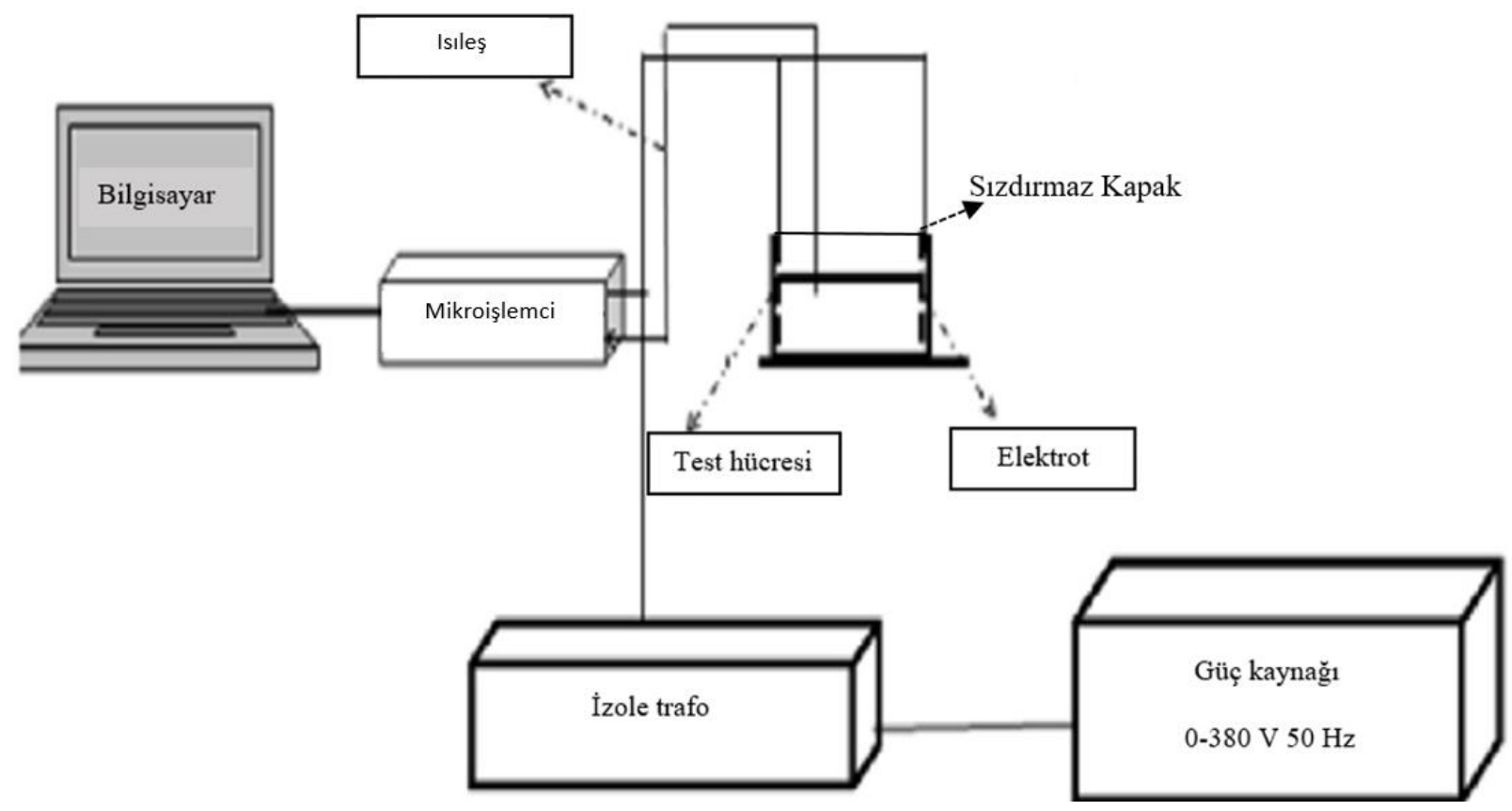

Şekil 1. Ohmik ısıtma sisteminin şematik gösterimi

\subsubsection{Elektriksel İletkenli Değişimi}

Ohmik 1sıtma işlemi sırasında meydana gelen elektriksel iletkenlik değişimi Eşitlik 1 ile tespit edilmiştir.

$\sigma, E . \dot{\mathrm{I}}\left(\frac{S}{m}\right)=\frac{I}{V} \times \frac{L}{A}$

Burada, E.İ elektriksel iletkenlik (S/m), I akım değerini, V voltaj değerini, L iki elektrot arasındaki mesafeyi (m), A ise elektrot temas alanın ifade $\left(\mathrm{m}^{2}\right)$ etmektedir.

Ohmik 1sıtma işlemi sırasında sıcaklıkla elektriksel iletkenlik değeri arasındaki ilişsi Eşitlik 2 ile incelenmiştir.

$\sigma=a \times T+b$

Eş. 2

Burada, $\sigma$ elektriksel iletkenlik $(\mathrm{S} / \mathrm{m}), \mathrm{T}\left({ }^{\circ} \mathrm{C}\right)$ sıcaklık değerini, a $\left(\mathrm{S} / \mathrm{m} \times{ }^{\circ} \mathrm{C}\right)$ ve $\mathrm{b}(\mathrm{S} / \mathrm{m})$ denklem sabitlerini ifade etmektedir.

Ohmik 1sitma süresince toplam harcanan enerji (THE) miktarı mikroişlemci yardımıyla elde edilen akım ve voltaj değerleri kullanılarak Eşitlik 3 ile hesaplanmıştır.

$\operatorname{THE}(J)=\sum(I \times V \times t)$

Burada, I akım değerini, V voltaj değerini, $t$ ise süreyi ifade etmektedir.

Ohmik 1sıtma süresince toplam harcanan enerji değerine bağl1 olarak ortalama güç (P) değeri Eşitlik 4 ardımıyla belirlenmiştir.

$\mathrm{P}(W)=\frac{\sum(T H E)}{t}$

Eş. 4

\subsubsection{Toplam Fenolik Madde (TFM) Miktarının Belirlenmesi}

Farklı işlem sürelerinde ohmik 1sıtma işlemine tabi tutulan örnekler hızla buz banyosunda ortam sicaklığına kadar soğutulmuştur. TFM içeriği Cemeroğlu (2010)'da belirtilen spektrofotometrik yönteme göre belirlenmiştir.

\subsubsection{Hidroksimetifurfural (HMF) Belirlenmesi}

Üzüm suyu örneklerinin HMF (Hidroksimetilfurfural) analizinde Tornuk ve ark. (2013)'nın metodu kullanılmıştır. $1 \mathrm{ml}$ üzüm suyu $1 / 5$ oranında seyreltmiş ve örnekler $0,45 \mu \mathrm{m}$ ' lik filtreden geçirildikten sonra viallere alınıp analiz yapılmıştır. HMF analizi için otomatik örnekleme özelliğine sahip Shimadzu marka HPLC (Schimadzu LC 20A, Japonya) cihazı kullanılmıştır. HMF analizinde C-18 (Zorbax Eclipse, XDB-C18) kolon kullanılmıştır. Kolon boyutları 25x0,46 mm ve kolon iç çap1 5 $\mu$ m'dir. Kromotogramlar Diode Array Detector (DAD)'da $284 \mathrm{~nm}$ dalga boyunda tespit edilmiştir. Enjeksiyon hacmi $10 \mu \mathrm{L}$ 'dir. Hareketli faz olarak \% 1'lik asetik asit içeren ultrasafsu ve asetonitril (95:5) kullanııııștır. Hareketli fazın akış hızı dakikada 1 mL'dir. Kolon sıcaklığı $25^{\circ} \mathrm{C}$ olarak ayarlanmıştır. Pik değerinde okunan alan değerleri, standart kalibrasyon eğrisi kullanılarak alana karşılık gelen konsantrasyon değerinin HMF miktarı "ppm" cinsinden hesaplanmıştır.

\subsection{5. İstatistiksel Değerlendirme}

Sonuçların istatistiksel değerlendirmesinde SPSS 16.0 (SPSS, IBM) paket programı kullanılmıştır. İşlemlerin etkileri arasındaki farklılıklar, Tamamen Rastgele Deneme Desenine göre, tek yönlü varyans (Post Hoc- Duncan testi) analizi ile belirlenmiştir. Güven aralığ 1 olarak \%95 seçilmiştir. 


\section{Araştırma Sonuçları ve Tartışma}

\section{1. Üzüm Suyunun Isttılması ve Ohmik Isitma Sırasında Elektriksel İletkenlik Değişimi}

$20{ }^{\circ} \mathrm{C}$ 'deki üzüm suyunun (\%14.8 SÇKM) $90^{\circ} \mathrm{C}$ 'ye ulaşması için 1sınma süresi $310.7 \pm 5.01 \mathrm{~s}$ olduğu tespit edilmiştir. İşlem süresi arttıkça ohmik 1sıtma tarafindan verilen enerjiye bağlı olarak sıcaklık değerinin artttığı ve ayrıca sicaklık artışının doğrusal olarak değişim gösterdiği belirlenmiştir. Ohmik 1sitma işlemi sırasında $90{ }^{\circ} \mathrm{C}$ 'de sabit sıcaklık değerinde tutulması amacıyla ohmik ısıtma işleminin açma/kapa işlemi yapılmıştır.
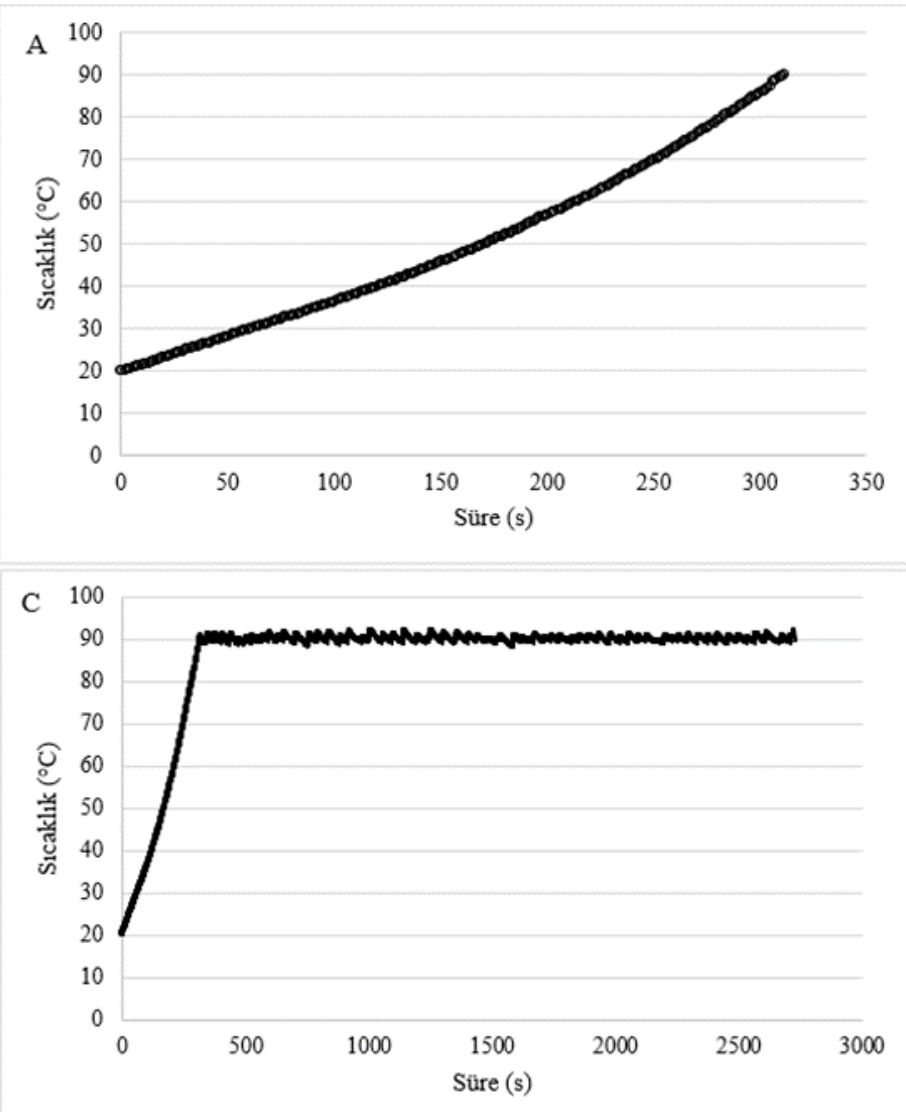

Buna göre farklı sabit sıcaklık değerinde tutma sırasındaki sıcaklık değişimi Şekil 2'de verilmiştir. Sabit sıcaklıktaki ortalama sıcaklık değerleri 20 dakika için $89.92 \pm 1.30{ }^{\circ} \mathrm{C}, 40$ dakika için $90.015 \pm 0.77{ }^{\circ} \mathrm{C}$ ve 60 dakika için $89.95 \pm 0.61{ }^{\circ} \mathrm{C}$ olduğu tespit edilmiştir. Ohmik 1sitma işleminde sistem kontrolünün kolay olması nedeniyle $90{ }^{\circ} \mathrm{C}$ 'de sabit sıcaklıkta tutulmuştur. Isıtma işleminde ohmik 1sıtma anahtarı açılınca üründen geçen alternatif akım ile ürün ısınmakta ancak ohmik ısıtma işleminde anahtar yardımıyla elektrik kesilmesi ile üründen elektrik akımı geçmemektedir. Bu işlem oldukça kolay ve uygulanabilirdir. Bu bağlamda özellikle ohmik 1sıtma işleminin en önemli özelliklerinden bir tanesi de sıcaklık kontrolü kolaylıkla sağlanmasıdır.

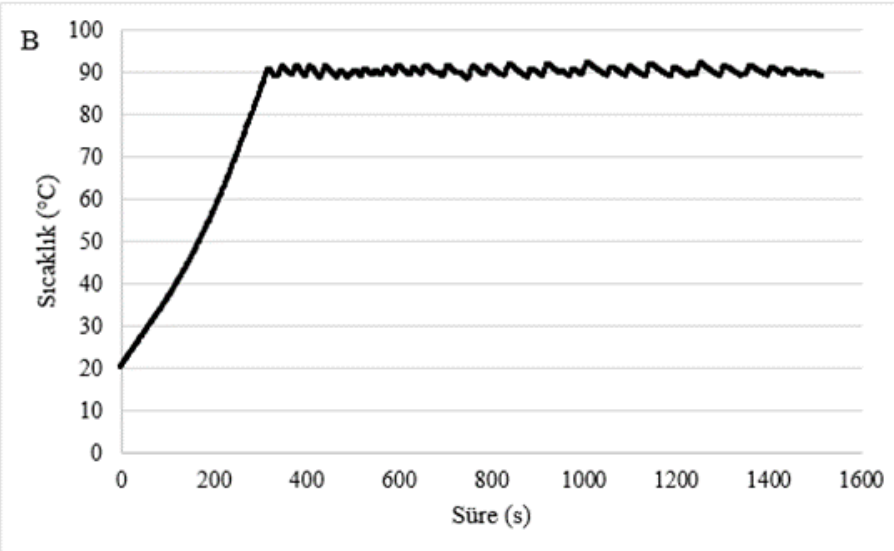

Şekil 2. Ohmik ısıtma uygulaması sırasında farklı süreler için sıcaklık değişimleri

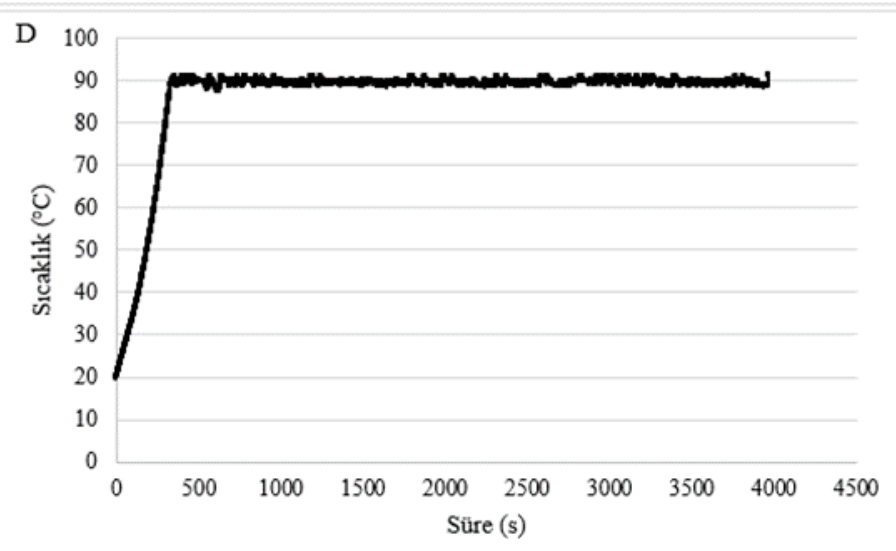

(A: 0 dakika, B: 20 dakika, C: 40 dakika, D:60 dakika)

Ohmik isıtma işleminde en önemli parametrelerin başında elektriksel iletkenlik değeri gelmektedir. Elektriksel iletkenlik değerinin sıcaklık arttıkça arttığ nedeni artan sıcaklık değerine bağlı olarak ürün içerisindeki moleküler hareketliliğin arttığı ve buna bağlı olarak elektriksel iletkenlik değerinin artmasıdır (İçier et al., 2004). Mevcut çalışmada da üzüm suyunun $20^{\circ} \mathrm{C}$ 'den $90{ }^{\circ} \mathrm{C}$ 'ye sıcaklık artışı sirasında elektriksel iletkenlik değerinin $0.144-0.582 \mathrm{~S} / \mathrm{m}$ arasında değiştiği ve Regrasyon katsayısının ise 0.98 değerinin üzerinde olduğu için doğrusal ilişkide olduğu tespit edilmiştir (Şekil 3). Üzüm suyunun $20^{\circ} \mathrm{C}$ 'den $90{ }^{\circ} \mathrm{C}$ 'ye kadar ssitılması sonucunda elektriksel iletkenlik değerinin farklı voltaj gradyanında $(20-40 \mathrm{~V} / \mathrm{cm}) 0.38-0.79 \mathrm{~S} / \mathrm{m}$ arasında değiştiği rapor edilmiştir (Içier et al., 2008). Başka bir yayında ise kırmızı üzüm suyunun (\%10.5-14 SÇKM) elektriksel iletkenlik değerinin farklı voltaj gradyanında $25{ }^{\circ} \mathrm{C}$ 'den $85{ }^{\circ} \mathrm{C}$ 'ye kadar isıtılmış ve elektriksel iletkenlik değerinin 0.4-1.0 $\mathrm{S} / \mathrm{m}$ arasında değiștiği rapor edilmiştir (Assawarachan, 2010). Güncel bir yayında ise üzüm suyu $30^{\circ} \mathrm{C}$ 'den $80^{\circ} \mathrm{C}$ 'ye kadar ohmik 1sıtma kullanılarak 1sitılmış ve elektriksel iletkenlik değerinin $0.25-0.81 \mathrm{~S} / \mathrm{m}$ arasında değiştiği ve voltaj gradyanının elektriksel iletkenlik üzerine etkisi olduğu rapor edilmiştir (Kumar et al., 2018). Farklı çalışmalarda üzüm suyu için farklı elektriksel iletkenlik değerinin elde edilmesi kullanılan üzümün içeriğine, ohmik 1sıtmanın özelliklerine (voltaj gradyanı, kullanılan miktar, test hücresi boyutu) bağlı olarak değişmektedir. Ayrıca literatürde vişne suyu, portakal suyu, limon suyu, çilek vb. meyve suları için elektriksel iletkenlik değerinin sıcaklık arttıkça arttığı ve elektriksel iletkenlik değerinin sıcaklık ile doğrusal ilişkisi olduğu rapor edilmiştir (Icier \& Ilicali, 2004; Icier \& Ilicali, 2005; Darvishi, Hosainpour, Nargesi, Khoshtaghaza, \& Torang, 2011; Castro, Teixeira, Salengke, Sastry, \& Vicente, 2004; Sarang, Sastry, \& Knipe, 2008).

Ohmik 1sıtma işlemi sırasında toplam harcanan enerji (THE) miktarının 35.73-138.37 kJ arasında değiştiği tespit edilmiştir. Beklenildiği üzere en düşük THE değeri 0 dakikalık işlem için 
$35.73 \pm 4.62 \mathrm{~kJ}$ olduğu belirlenirken işlem süresinin artmasına bağlı olarak açma/kapama işleminin etkisi ile toplam harcanan enerji değerinin arttığı belirlenmiştir. Ayrıca artan sabit sıcaklıkta tutma süresinin toplam harcanan enerji değeri arasında istatistiksel olarak anlamlı bir fark olduğu belirlenmiştir $(\mathrm{p}<0.05)$.
Bunun yanısıra işlem sırasında ohmik 1sıtma işleminin ortalama güç değeri ise 114.90-35.38 W arasında değiştiği belirlenmiş ve toplam harcanan enerji değerinin aksina işlem süresi arttıkça güç değeri azalmıştır $(\mathrm{p}<0.05)$.

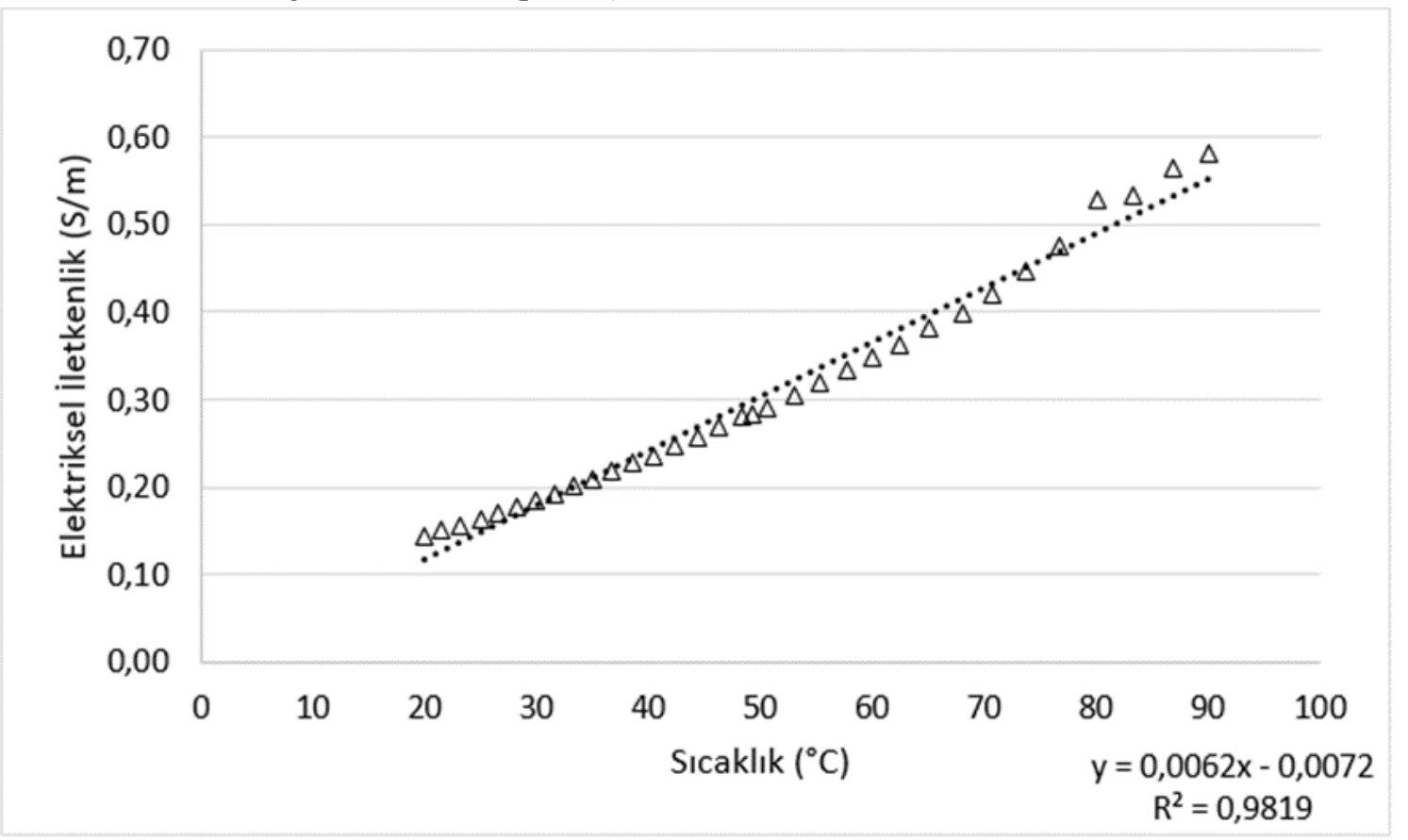

Şekil 3. Ohmik ısıtma sırasında sıcaklık değerine bağlı olarak elektriksel iletkenlik değişimi

\section{2. Üzüm Suyunun Ohmik Isitılması Sırasında Toplam Fenolik Madde Miktarı ve Hidroksimetilfurfural Değişimi}

Üzüm suyu özellikle içerdiği toplam fenolik maddelerce zengin bir üründür. Mevcut çalışmada $90{ }^{\circ} \mathrm{C}$ 'de sabit sıcaklıkta bekletilen üzüm suyunun TFM miktarı ve HMF içeriğine bağlı değerler Çizelge 1'de verilmiştir. İşlem süresinin artmasına bağlı olarak SÇKM içeriğinin \%15.3 SÇKM içeriğine kadar yükselmiş olduğu tespit edilmiştir. Elde edilen üzüm suyunun SÇKM içeriği $\% 14.8$ 'e ayarlanmış ve kalite kriterleri incelenmiştir. Buna göre TFM miktarı Gallik asit eşdeğeri cinsinden 466-367 mg/L olduğu belirlenmiştir. En düşük TFM miktarı 60 dakikalık tutma süresinde elde edilirken, en yüksek TFM miktarı ise 0. dakikada elde edilmiştir. Artan işlem süresi ile TFM miktarı arasında istatistiksel olarak anlamlı bir fark olduğu belirlenmiştir. Yildiz, et al. (2009) nar suyunu ohmik 1sitma kullanarak $90{ }^{\circ} \mathrm{C}$ 'ye kadar 1sıtmışlar ve sabit sıcaklıkta $\left(90^{\circ} \mathrm{C}\right)$ farklı tutma sürelerinde $0-12$ dak arası 1sıl işleme tabi tutmuşlardır. İșlem süresinin TFM miktarı üzerine etkisi olmadığını rapor etmişlerdir. Ancak mevcut çalışmada işlem süresinin uzun olmasının bu azalmaya neden olabileceği düşünülmektedir. Sabancı \& Icier, (2019) ohmik 1sıtma kullanarak vişne suyunu \%65 SÇKM içeriğine kadar konsantre etmiş, artan işlem süresinin TFM miktarı üzerine etkili olduğunu vurgulamışlardır.

Hidroksimetilfurfural için elde edilen miktarlar ppm cinsinden Çizelge 1'de detaylandırılmıştır. Üzüm suyunun 90 ${ }^{\circ} \mathrm{C}$ 'ye kadar isınmasında elde dilen HMF içeriğinin $0.60 \mathrm{ppm}$ düzeyinde olduğu belirlenirken artan işlem süresinin 60 dakika olması nedeniyle $4.71 \mathrm{ppm}$ olarak belirlenmiştir. $90{ }^{\circ} \mathrm{C}$ 'de tutma süresinin HMF içeriği üzerinde etkisi olduğu tespit edilmiştir $(\mathrm{p}<0.05)$. Sabanci et al. (2017) vişne suyunu $65^{\circ} \mathrm{C}$ 'de 3 farklı voltaj gradyanında \%40 SÇKM içeriğine kadar konsanre etmişler ve HMF içeriğinin 2.70-5.4 mg/L arasında değiştiğini belirtmiş ve artan işlem süresinin HMF oluşumu üzerine etkisi olduğunu rapor etmişlerdir.

Tablo 1. Çizele 1. Ohmik ısıtma işlemi sırasında farklı sürelerde elde edilen Toplam Fenolik Madde (TFM) miktarı ve Hidroksimetilfurfural (HMF) miktarı

\begin{tabular}{lcccc}
\hline Kalite & \multicolumn{4}{c}{ İşlem süresi (dak) } \\
Kriterleri & 0 & 20 & 40 & 60 \\
\hline TFM (mg/L) & $466.37 \pm 33.85^{\mathrm{c}}$ & $438.87 \pm 69.82^{\mathrm{c}}$ & $407.13 \pm 8.46^{\mathrm{b}}$ & $367.63 \pm 24.85^{\mathrm{a}}$ \\
HMF (ppm) & $0.60 \pm 0.12^{\mathrm{a}}$ & $1.91 \pm 0.16^{\mathrm{b}}$ & $2.48 \pm 0.25^{\mathrm{c}}$ & $4.71 \pm 1.22^{\mathrm{d}}$ \\
\hline
\end{tabular}


381470-8.00011-6

Icier, F., \& Ilicali, C. (2004). Electrical conductivity of apple and sourcherry juice concentrates during ohmic heating. Journal of Food Process Engineering, 27(3), 159-180.

\section{Sonuç}

Sonuç olarak, ohmik 1sıtma kullanarak sabit voltaj gradyanında $(13 \mathrm{~V} / \mathrm{cm})$ üzüm suyu $20{ }^{\circ} \mathrm{C}$ 'den $90{ }^{\circ} \mathrm{C}$ 'ye kadar 1sıttılmış ve kontrollü şekilde $90{ }^{\circ} \mathrm{C}$ sabit sicaklıkta tutulmuştur. Isıtma için gerekli olan toplam işlem süresinin $311 \pm 5.0 \mathrm{~s}$ olduğu belirlenmiştir. Artan sıcaklığa bağlı olarak elektriksel iletkenlik değerinin arttığı tespit edilmiştir. Sıcaklık ile elektriksel iletkenlik arasında $\% 95 \mathrm{R}^{2}$ değerinin üstünde doğrusal ilişki olduğu bulunmuştur. Üzüm suyunun 1sıtılması için $35.73 \pm 4.62 \mathrm{~kJ}$ toplam harcanan enerji gereksinimi varken artan sabit sicaklıkta tutma süresine bağlı olarak toplam harcanan enerji miktarında artış olduğu belirlenmiştir. Ancak ohmik 1sıtma işleminin ortalama güç değerinin ise artan sabit sıcaklıkta tutma süresine bağlı olarak azaldığg belirlenmiştir. Üzüm suyunun TFM içeriğinin yüksek olduğu bilinmektedir. Sabit sıcaklıkta tutma süresinin artmasına bağlı olarak TFM içeriğinin olumsuz etkilendiği belirlenmiştir. Ancak artan sabit sicaklıkta tutma süresinin HMF üzerinde olumlu etkisi olduğu ve HMF miktarının artmasına neden olduğu tespit edilmiştir. Ohmik ısıtma işleminin kalite özellikleri üzerine etkisi olduğu ve artan sabit sıcaklıkta tutma süresinden olumsuz etkilendiği tespit edilmiştir.

\section{Kaynakça}

Akarca, G., \& Tomar, O. (2018). Siyah ve Yeşil Çay İle Üretilen Kombucha Çaylarının Antimikrobiyal ve Antioksidatif Özellikleri. European Journal of Science and Technology, 14, 96-101. doi: 10.31590/ejosat.478054

Assawarachan, R. (2010). Estimation model for electrical conductivity of red grape juice. International Journal of Agricultural and Biological Engineering, 3(2), 52-57. doi: 10.25165/ijabe.v3i2.96

Atik, İ., Şevik, R., \& Karasu, S. (2019). Soğuk Press Kiraz (Prunus avium) Çekirdeği Yayının Fizikokimyasal Özellikleri, Yağ Asidi, Sterol, Tokoferol ve Fenolik Bileşen Karakterizasyonu. European Journal of Science and Technology, 17, 959-965. doi: 10.31590/ejosat.656768

Bayram, Y., Torlak, Y., \& Sağdıç, O. (2019). Üvez Meyvesinin Antioksidan Aktivitesi. European Journal of Science and Technology, 16, 933-939. doi: 10.31590/ejosat.589736

Baysal, T., İçier, F., \& Baysal, H. A. (2011). Güncel Elektriksel Isıtma Yöntemleri (1. Basım). Sidas Medya Yayınları.

FAO. (2019). Food and Agriculture Organization of the United Nations. FAOSTAT. Retrieved from http://www.fao.org/faostat/en/\#data/QC

Guida, V., Ferrari, G., Pataro, G., Chambery, A., Di Maro, A., \& Parente, A. (2013). The effects of ohmic and conventional blanching on the nutritional, bioactive compounds and quality parameters of artichoke heads. LWT - Food Science and Technology, 53(2), 569-579. doi: 10.1016/j.lwt.2013.04.006

İcier, F. (2010). Ohmic blanching effects on drying of vegetable byproduct. Journal of Food Process Engineering, 33(4), 661-683. doi: 10.1111/j.1745-4530.2008.00295.x

İçier, F. (2012). Ohmic Heating of Fluid Foods. In Novel Thermal And Non-Thermal Technologies For Fluid Foods (pp. 305-367). Elsevier Inc. doi: 10.1016/B978-0-12-
İçier, F., \& Ilicali, C. (2004). Electrical conductivity of apple and sourcherry juice concentrates during ohmic heating. Journal of Food Process Engineering, 27(3), 159-180. doi: 10.1111/j.1745-4530.2004.tb00628.x

Içier, F., Yildiz, H., \& Baysal, T. (2008). Polyphenoloxidase deactivation kinetics during ohmic heating of grape juice. Journal of Food Engineering, 85(3), 410-417. doi: 10.1016/j.jfoodeng.2007.08.002

İncedayi, B., Seyhan, B., \& Çopur, Ö. U. (2019). Ohmik Isıtma Destekli İşlemlerin Gıdalarda Kullanımı ve Kalite Üzerine Etkisi Use of Ohmic Heating Assisted Treatments in Foodstuffs and Impact on Quality. Bursa Uludağ Üniversitesi Ziraat Fakültesi Dergisi Journal of Agricultural Faculty of Bursa Uludag University, 33(2), 341-354.

Karadağ, A. (2019). Türkiye'deki Bazı Tıbbi ve Aromatik Bitkilerin Antioksidan Potansiyalleri ve Fenolik Kompozisyonlar1. European Journal of Science and Technology, 16, 631-637. doi: 10.31590/ejosat.592711

Kiraca, M. A., \& Şenol, M. A. (2017). Türkiye Bağcılığında Ekonomik Durum Analizi. Nevşehir Bilim ve Teknoloji Dergisi, 6, 122-131. doi: 10.17100/nevbiltek.287811

Kumar, T., Smith, D. D., Kumar, S., \& Vimla, B. (2018). Effect of Voltage Gradient and Temperature on Electrical Conductivity of Grape (Vitis vinifera L.) Juice during Ohmic Heating. Article in International Journal of Current Microbiology and Applied Sciences, 7(5), 1914-1921. doi: 10.20546/ijcmas.2018.705.224

Louarme, L., \& Billaud, C. (2012). Evaluation of ascorbic acid and sugar degradation products during fruit dessert processing under conventional or ohmic heating treatment. LWT - Food Science and Technology, 49(2), 184-187. doi: 10.1016/j.lwt.2011.12.035

Sabanci, S., Cevik, M., Cokgezme, O. F., Yildiz, H., \& Icier, F. (2018). Quality characteristics of pomegranate juice concentrates produced by ohmic heating assisted vacuum evaporation. Journal of the Science of Food and Agriculture, 4. doi: 10.1002/jsfa.9474

Sabanc1, S. (2017). Ohmik 1sitma destekli vakum altında evaporasyon sisteminin kurulumu, performans değerlendirmesi, işlemin deneysel ve kuramsal incelenmesi/Setting up and performance evaluation of ohmic heating assisted vacuum evaporation system, and experimental investiga [Doktora tezi, Fen Bilimleri Enstitüsü, Ege Üniversitesi]. Retrieved from https://tez.yok.gov.tr/UlusalTezMerkezi/tezSorguSonucYe ni.jsp

Sabanc1, S., \& Icier, F. (2019). Effects of Vacuum Ohmic Evaporation on Some Quality Properties of Sour Cherry Juice Concentrates. International Journal of Food Engineering, 15(9). doi: 10.1515/ijfe-2019-0055

Yildiz, H., Bozkurt, H., \& Icier, F. (2009). Ohmic and conventional heating of pomegranate juice: Effects on rheology, color, and total phenolics. Food Science and Technology International, 15(5), 503-512. doi: $10.1177 / 1082013209350352$ 